\title{
IMPACT OF TIME ZONES ON FORECASTING OF EXCHANGE MARKET BASED ON DISTRIBUTION OF EXPECTED VALUES
}

\author{
Nijolè Maknickiené ${ }^{1}$, Algirdas Maknickas ${ }^{2}$ \\ ${ }^{1}$ Department of Finance Engineering, Vilnius Gediminas Technical University, \\ Sauletekio al. 11, Vilnius, Lithuania \\ ${ }^{2}$ Department of Information Technologies, Vilnius Gediminas Technical University, \\ Saulètekio al. 11, Vilnius, Lithuania \\ E-mails: 'nijole.maknickiene@vgtu.lt (corresponding author); ${ }^{2}$ algirdas.maknickas@vgtu.lt
}

\begin{abstract}
Forecasting of chaotic changes of exchange rates usually is based on historical data and depends on the choice of time intervals. This study seeks to develop new forecasting method based on data of different time zones. This paper demonstrates how the using of London and New York divisions of the trading day allows getting additional information from predicting exchange rates. This was modelled with the help of ensemble of EVOLINO for obtaining of predictions of the distribution of expected values. The obtained results show that double forecasts evaluation reveals a possible trend in the exchange market and enriches the choice of real-time trading strategies.
\end{abstract}

Keywords: artificial intelligence, evolino, ensemble, forecasting composition, investment, speculation, support system.

JEL Classification: F31; F65; G15; G17.

\section{Introduction}

Speculation in finance market in real time gives the opportunity for investor to be independent from the living space, their home country's level of development and public policy. Speculation is based on knowledge of using the latest technologies and reliable tools that can help people of all ages and social status to create their own well-being.

Global exchange market is monitored in real time around the world and it has the highest average daily turnover in all financial market. Cetina (2005, 2015) examined in detail processes, architecture and trends of global exchange market and proposed media-institution model. Rutkauskas and Kvietkauskiene (2013) investigated investment in global market based on Lithuanian data. Trading futures contracts in global market was presented in paper by Stasytyte and Martinkutè-Kaulienè (2014). Lall (2015) examine two regulatory regimes that are central to the efficiency and stability of the global financial system. The main activities in finance markets are investment and speculation. Differences between percipients in finance markets were investigated by Fridson (2012). Role of investors and speculators was researched by Radu (2013). Other authors (Baker et al. 2016) reasoned in their paper: "When investors disagree, speculation between them alters equilibrium prices in financial markets".
Efficiency of investment and speculation in exchange market depends on using of different tools for prediction the finance market. Ter Ellen et al. (2013) proposed three different time-varying rules depending conditional on a number of different factors. Melvin et al. (2013) provide quantitative analytical tools that can be useful in evaluating currency manager skill in terms of portfolio tilts and timing. Paper of authors (Schmitt, Westerhoff 2014) presented developed trading model based on statistical properties of finance market. Basic forecasting technics are investigated in book written by Pandey (2015). Prediction of finance market behaviour by model based on regression presented in paper (Roy et al. 2015).

Artificial intelligence also is being used as the main tool in forecasting of finance market. Sermpinis et al. (2013) introduces a hybrid neural network architecture of Particle Swarm Optimization and Adaptive Radial Basis Function and a time varying leverage trading strategy. Evans et al. (2013) investigated model based on neural networks and genetic algorithms for intra-day speculation in exchange market. Rout et al. (2014) proposed accurate predicting model combining an adaptive autoregressive moving average (ARMA) architecture and differential evolution (DE) based training. Deng et al. (2015) proposed prediction of exchange market model based on computational intelligence. Some of authors are using the ensembles 
of neural networks for predicting finance markets (Pulido et al. 2013, 2014; Joao et al. 2014; Pulido, Melin 2015). The ensemble architecture of neural networks provides new opportunities to the forecasting process.

When future prediction is treated as continuation of the past, the time there is significance component of forecasting. Speculators are making decisions in local countries but trading in global finance market. Authors (Stein, Daude 2007) show the significant negative effect of time zones to investment. Different trading strategies were investigated by authors (Dacorogna et al. 1995), rules of these strategies take into account an opening hours of market, time zones and local holidays.

Technology of real time allows speculators to be free from location and time of day. Author (Greene et al. 2013) presents invention related to the online trading system that allows users to open accounts in "real time", and the user is able to perform trading operations immediately after the account is opened. Authors (Kong et al. 2015) investigated cloud enabled real time platform for trading. Author of paper (Ince 2014) researched that panel method and real time data increases the predictability of exchange rates. Kvietkauskiene (2013) investigated adequate portfolio strategies and monitored them by real time demo platform.

When future is being recognized like distribution of opportunities, the choice of time of decision making is very significant. Model based on distribution forecasting and prediction interval was proposed by researches (Fan, Hyndman 2012; Masteika et al. 2013). Bańbura et al. (2015) constructed the model for large data sets based on distribution of expected values.

The aim of our research is the investigation of the impact of time zones on forecasting of exchange rates. We are using the support system tool for speculator in exchange market based on EVOLINO (EVolution of recurrent systems with Optimal LINear Output) ensemble. The time is an important component in forecasting, which reveals certain characteristics of the global market, which we seek to analyse in this article.

The study includes two main tasks: 1) to examine whether the London, New York and Tokyo markets working hours have an impact on the exchange rate fluctuations, maximal and minimal values achievement; 2) Create a method which uses the time zone offset receipt of additional information, and give speculators an advantage compared to the uninformed market participants.

\section{Forecasting of finance market in real time}

Individual investors and speculators face rapidly changing trading conditions: growth of the apps industry for smartphone platforms, variety of predictive analytics and visualization. Decision making does not require long time if it is using a reliable support system. Successful marketing requires a solid strategy and needs discipline to follow the rules. The trading time is one of components in discipline following rules.

\subsection{Stochastic motion and AI}

The simplest description of motion would be "measurement of change". When we start the observation of somewhat mechanical motion, we always want to compare that process with similar processes of the same area. In other words, we could describe each mechanical motion by speed of change. If we have in physics the two changes of speed for two similar processes, the ratio of that speeds could be the "initial motion" for measurement of observable processes.

Such kind of description does not work for stochastic motion. Wiener (1923) proposed to describe Brownian motion, which occurs frequently in pure and applied mathematics, economics, quantitative finance, and physics, in terms of a random Fourier series. If we have the price evolution of financial instrument such as stock option, we can apply Black-Scholes partial differential equation This equation is depending on stock price $S$ and time $t$, risk-free interest rate $r$, and the volatility of the stock $\sigma$. The derivation of Black-Scholes partial differential equation based on geometric Brownian motion of the price of the underlying asset (typically a stock) (Hull 2008), where the Brownian motion is the Wiener process. The basic idea of derivation is grounded on proposition that ratio of speed of change of stock price and value of price is linear dependent on Wiener process. Obtained partial differential equation should be solved for payoff of an option as a function of stock price and a time, where stock price, Wiener process speed are stochastic variables and time is continuous variable.

On the other hand, the price evolution of financial instrument such as exchange rates can be predicted by applying methods developed in artificial intelligence (Maknickas, Maknickienè 2015). Authors proposed exchange rates prediction model based on recurrent neural network ensemble. Each item of the ensemble consist of four interconnected long short-term memory (LSTM) cells treated as recurrent neural network (RNN) proposed by 
Hochreiter and Schmidhuber (1997). An LSTM block may be described as a "smart" network unit that can remember a value for an arbitrary length of time. An LSTM block contains gates that determine when the input is significant enough to remember, when it should continue to remember or forget the value, and when it should output the value. The gates are of two kinds: the gates which multiplies outputs of logistic functions and gates which multiplies recurrent output of gates with output of logistic functions. Finally, LSTM was also trained by applying of genetic algorithm for obtaining the best combination of weights which minimize prediction error between predicting and historic data in recurrent neural network learning cycle. One recurrent neural network can predict just the one point, but the future is a distribution of possibilities. So, single network of an ensemble predicts single prediction point and whole ensemble forms distribution of possible predictions.

The most importance part of model is preparation of input data. First of all, we know that financial instruments, such as stock price of exchange rate, are stochastic processes. So, the ratio of price speed of change and price value is linear dependant on Wiener process. In such case, we can replaced Wiener process by other stochastic moving price of commodity market, for example XAU/USD (price of gold in US dollars), by adding this data as additional input into the LSTM recurrent neural network, where first input is historic values of exchange rates. Therefore we can say that ensemble of LSTM recurrent neural networks works as solver of stochastic PDE for treated financial instrument.

\subsection{Support system for speculator in exchange market}

Our support system was presented in conference (Maknickas, Maknickiene 2015). This process consist of 5 stages: preparation of historical data, prediction by ensemble of EVOLINO, prediction assessment, selection of portfolio, verification in real time demo market.

The selection of historical data ranges is based on the orthogonality between exchange rate, what we can predict and data range of historical data of gold price in US dollars (Maknickas, Maknickiene 2012). Preparation of historical data depends on selecting of time zone. We have so far used the New York "open", "high", "low" and "close" historical data. We doubt, why we does not use London time and, thus, decided to investigate it.

Our predicting model is based on open source evolutionary recurrent neural network EVOLINO, which was developed by scientists (Schmidhuber et al. 2005, 2006; Wierstra et al. 2005). Our model (Maknickiene, Maknickas 2013) consist of 176 EVOLINO's ensemble, which can predict in parallel and use different historical data sets.

The result of prediction is multimodal distribution of expected values. Assessment of prediction takes account the main modes, skew and kurtosis according to last known value.

Decision of portfolio optimisation takes into account the probabilities of profit and losses. Portfolio orthogonality reduces the trading risk in critical exchange market situations (Maknickienè 2014).

The best verification of any support system is trading in real time for long period. We used several portfolios with different level of risk level and different strategies. The evaluation of profit, profit from trade and mean absolute percentage error allows to compare different strategies.

The support system requires multi-core hardware resources for timely data processing using MPI library-based parallel computation.

\subsection{Time zones and data for prediction}

Global exchange market is independent from time zones, the price is the same in all of them, but the division of the intervals (day, week, month...) are different. Most forecasting tools use time series of exchange rates historical data obtained from the trading platform, which has the ability to choose the time zone.

"Open" and "close" values depend on choice of market. London market is opening at 08:00 and closing at 17:00. New York time zone has 5 hours shift from London market opening at 08:00 and closing at 17:00 in local time, Tokyo time zone has +9 shift and market opening at 09:00 and closing at 18:00 local time. Shift of time zones of London, New York and Tokyo presented in Figure 1.

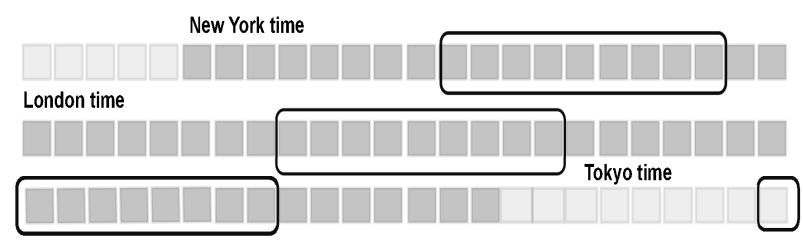

Fig. 1. Shift of time zones of London, New York, Tokyo. Forex markets time signed by black round box. (Source: created by the authors according to the Forex market... 2006)

Can these differences be useful in decisionmaking? The maximal and minimal values have weak dependence on time zones. Following values 
can occur in the same or in different trading time intervals. Maybe, we can use data of New York market, but trade in London or Tokyo time or vice versa.

\section{Impact of time zones on trading in exchange market}

Our research investigate two aspects of time intervals in exchange market. First of them the opinion of individual investors, that most activity of London and New York finance market is at the time when London markets is open, was analysed. Distributions of maximal and minimal exchange rates values can examine this opinion. Second investigation analyses the opportunity to get benefit from difference of London and New York markets time, based on distributions of expected values. In Figure 2 shift of time zones of London and New York is shown. The time series is divided into different ranges of day (vertical lines) and has different open $U K$-close $U K$ and open $N Y$-close $N Y$ values. Max and min values are the same in this case, but may be otherwise if the values are within the time zones shift area (between the dotted and solid lines).

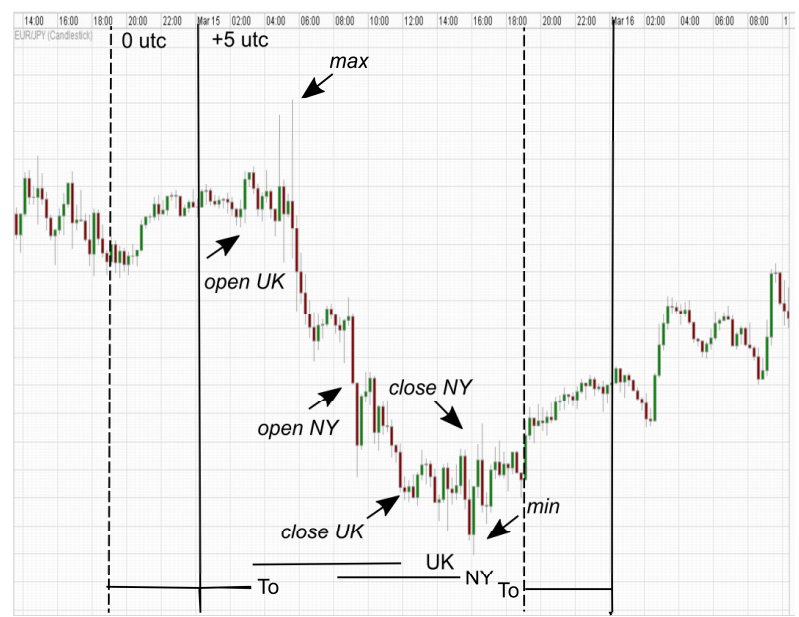

Fig. 2. Shift of time zones of London, New York and time series of exchange rate

(Source: compiled by authors)

Predictions made by using open-close historical data will be different in the UK and NY time zones, but prediction made on max and min data should be the same in most cases. The trader can win 5 hours calculation time if he will use UK min or max historical data, but will trade on NY time.

\subsection{Achieving time of daily maximal and minimal values}

Euro and United States dollars rate (EUR/USD) was selected as main currency of Europe Union and US. We selected New York time as our trading time, so distributions of reached maximal and minimal values for given time use this time scale division. Distribution of maximal data values in the year 2015 is shown in Figure 3.

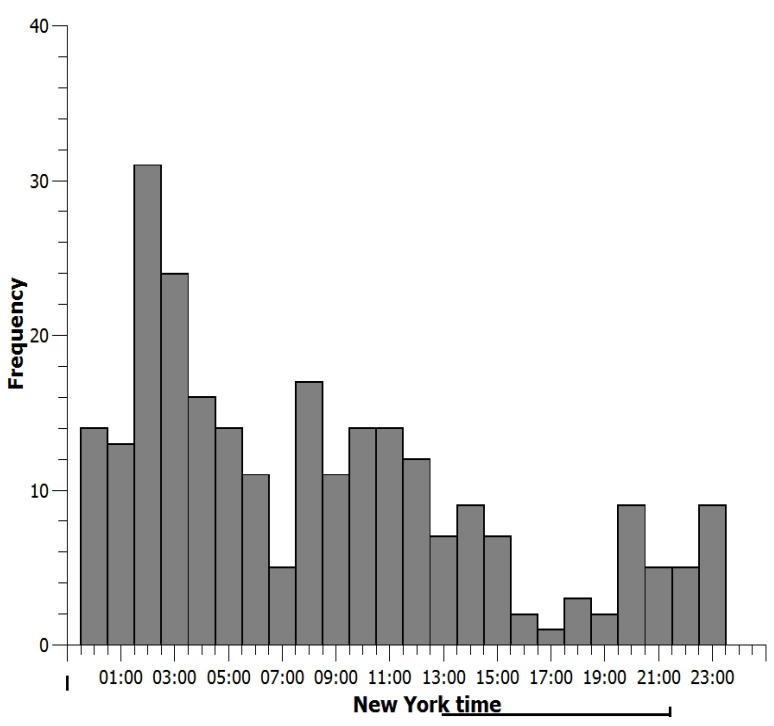

Fig. 3. Distributions of maximal daily EUR/USD value for given day time scale (Source: compiled by authors)

There we can see that he most frequency of reached maximal values is at 02:00-03:00 o'clock in New York time scale, when New York markets are closed, London market is open only 1 hour and Tokyo market is working last 2 hours. Minimal frequency was reached at 16:00-19:00, when New York market closing, London and Tokyo markets are closed. Distribution of minimal EUR/USD values is presented in Figure 4. The highest reached frequencies of minimal values are in interval from 00:00 to 12:00, with the peak at 08:00 in New York time. There are no direct dependences between these markets in different time intervals.

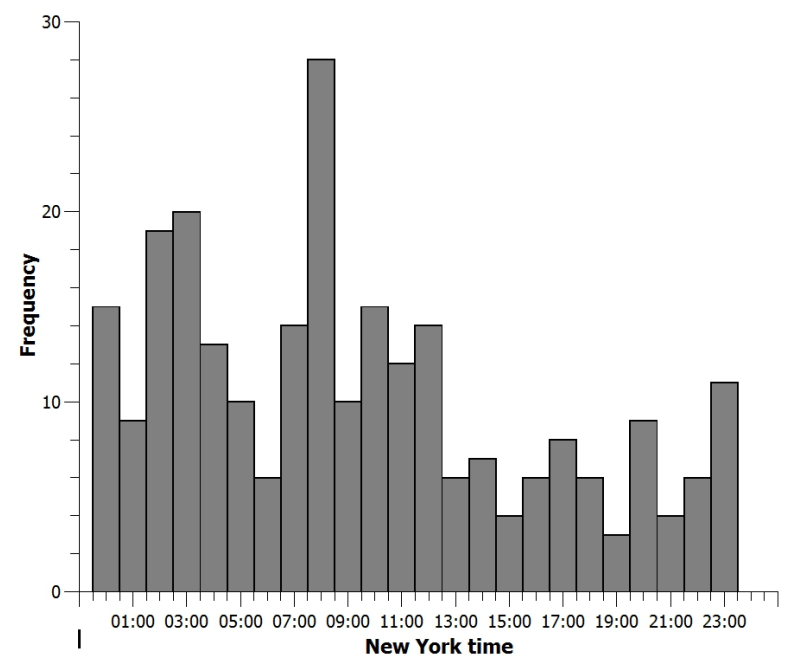

Fig. 4. Distributions of minimal daily EUR/USD value for daily time scale (Source: compiled by authors) 
United States dollars and Japanese Yen rate (USD/JPY) was selected as second pair of currencies. Distribution of reached maximal data for daily time scale is shown in Figure 5.

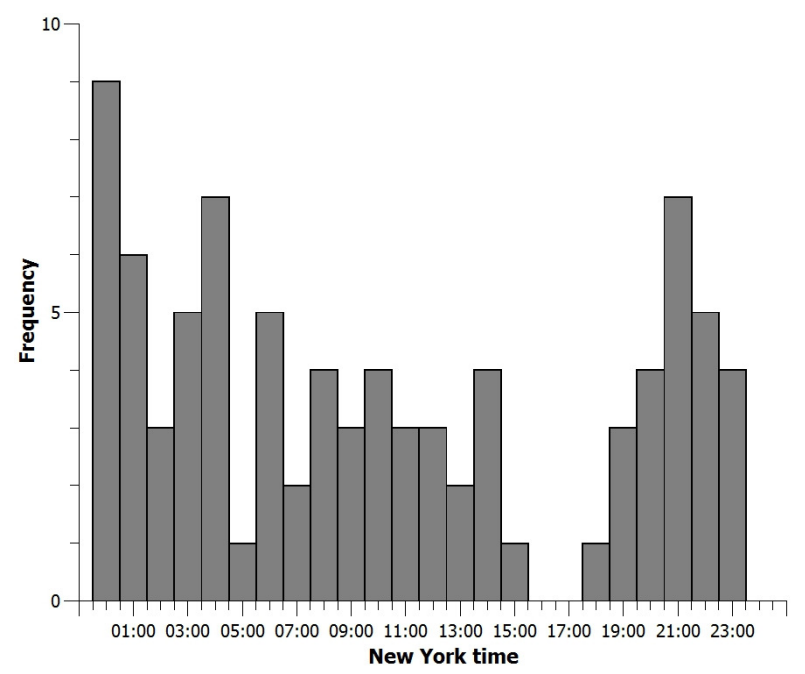

Fig. 5. Distributions of maximal daily USD/JPY for given day time scale (Source: compiled by authors)

Distribution looks very casual with zeros at 16:00-18:00 in New York time, when New York market is closing, London and Tokyo markets are closed. Distribution of minimal values of USD/JPY is shown in Figure 6. This distribution is also random with zero values at 05:00-06:00, only when London market is open and at 08:00, when London and New York market is open.

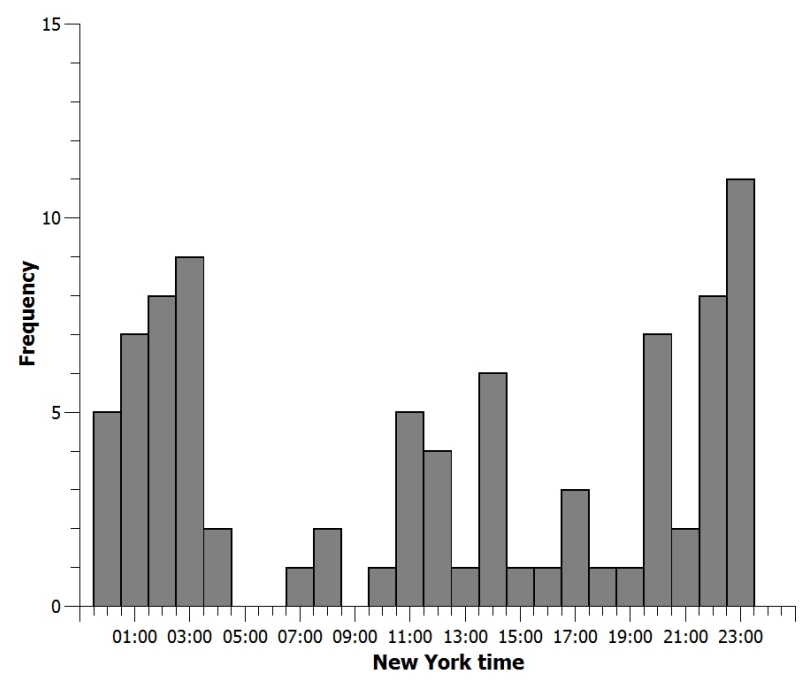

Fig. 6. Distributions of minimal daily USD/JPY value for given time scale (Source: compiled by authors)

Dependences between market activity and working time of three different markets was not found. So the opinion of individual investors, that market is more active, when London and New York markets are open, is myth. "Open" and "close" values of exchange market are not so significant for speculators and investors. Using these values as historical data in forecasting tools or as "teacher" in artificial intelligence tools does not make sense. Maximal and minimal values are significant as extremes, but it is important what time base we select. It makes sense to be independent from the time base and to get benefit from shift in time of different time zones.

\subsection{Shift between United Kingdom time and New York time}

Second our investigation analyse the opportunity to get benefit from difference of London and New York markets time by using our support system for speculator in exchange market based on ensemble of EVOLINO. "Close" rate value is at the same time fixed value and in real time it can be the last known value, so for better visualisation and calculation we selected "close value" of UK market.

Speculator in exchange market platform (for example Oanda) can choose the time zone UK (United Kingdom) or NY (New York). The time intervals that are used in the preparation of historical data also comply with the following time zones. So we can predict by both data sets and compare both distributions of expected values.

The Figure 7 presents EUR/USD forecasting distribution based on UK historical data of closing values of earlier day, as last known value, and is marked by dash line. Decision is not clear because the mode is left from dash line, but distribution is skewed to right.

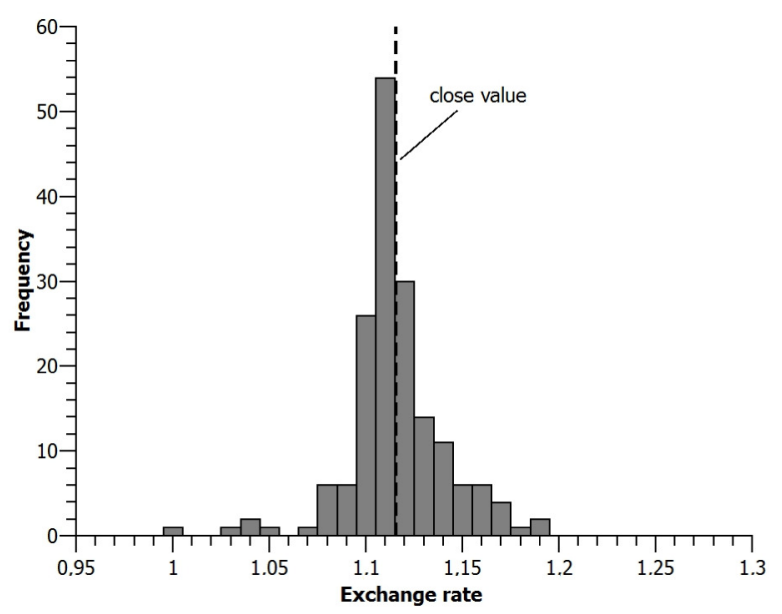

Fig. 7. Distributions of expected values of daily EUR/USD based on UK historical data (Source: compiled by authors) 
The forecasting distribution of EUR/USD based on NY historical data is presented in Figure 8. Decision there is "buy". New York time zone is five hours later, then London, so no doubt, that value of EUR/USD will achieve 1.12 in New York day time. The selected case does not have a clear solution, and the UK forecast is questionable. The doubts dissipated when NY distribution is analysed.

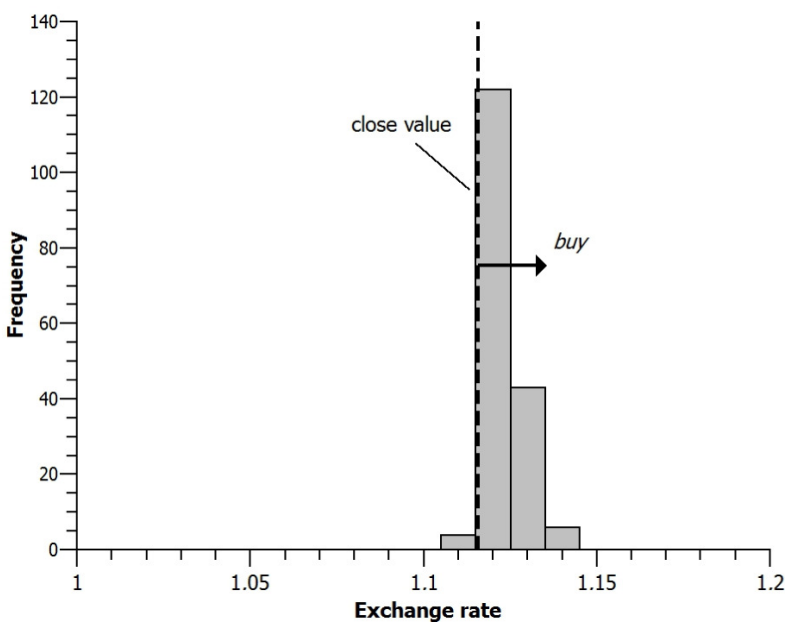

Fig. 8. Distributions of expected values daily EUR/USD based on NY historical data

(Source: compiled by authors)

In Figure 9 USD/JPY forecasting distribution, made on UK historical data is presented. The decision there is risky, because the "close" value is between two significant modes.

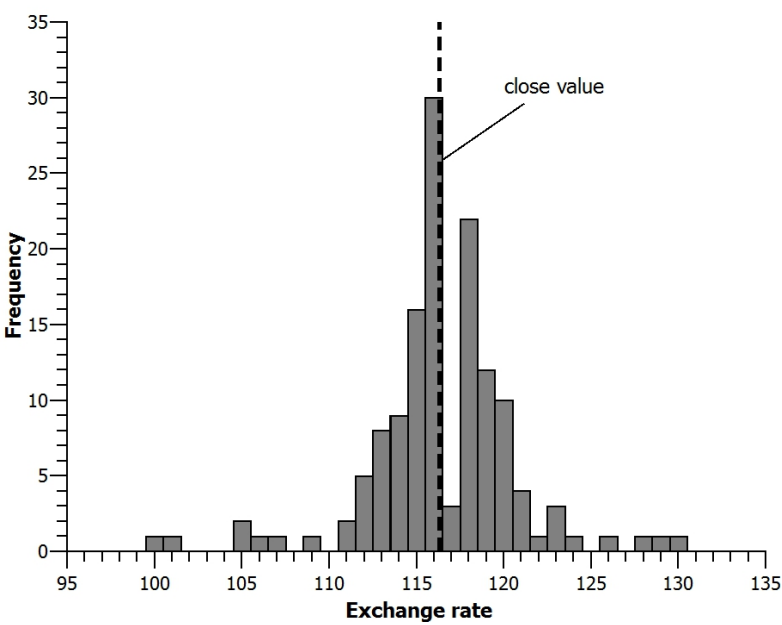

Fig. 9. Distributions of expected values of daily USD/JPY based on UK historical data (Source: authors)

Distribution of expected values of USD/JPY based on NY historical data is presented in Figure 10. The decision there is "sell", because mostly all distribution is left to closing value.

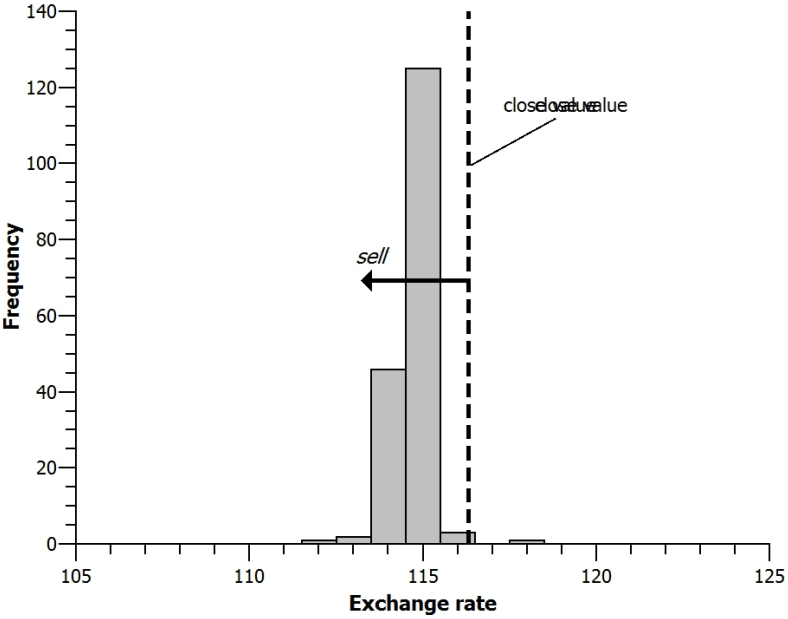

Fig. 10. Distributions of expected values daily USD/JPY based on NY historical data (Source: compiled by authors)

Double forecasting in this case also makes decision more clear. The rule of the decision can be written as - UK risky "sell" + NY "sell" = "sell".

The shift of the time zones helps speculators to make decision by using forecasting distribution based on NY historical data. Two distributions calculated on maximal or minimal data of different time zones gives more useful information for speculators in exchange market. The two predictions enhances the decision-making, when the predicted directions of change of currency prices are identical and warns about the risks involved in the decision when predicted changes of exchange rates are in opposite. The composition of two distributions provides additional information required for the decision making:

$$
\begin{aligned}
& \text { UK "buy" + NY "buy" = "buy", } \\
& \text { UK "sell" + NY "sell" = "sell", } \\
& \text { UK "buy" + NY "sell" = risky "sell", } \\
& \text { UK "sell" + NY "buy" = risky "buy". }
\end{aligned}
$$

When predictions of UK and NY are different, decisions are risky and require more analytics of distributions values: standard deviation, modes, kurtosis, probabilities and last known value. Perhaps simply the best solution in this case is a "hold", when speculator is waiting new signals of market and does not transactions. These rules can be easily programed and adapted to modern technology.

Speculators and investors can choose trading strategies based on their individual needs, personality characteristics and employment time. They acquires an advantage in making investment decisions compared with uninformed market players.

Modern investors and speculators seek advantage by using new technologies, analytics based applications, specifically selected information. For 
them it is important to have a reliable support system, adapted to individual needs.

Our proposed time-shift method is one of the possibilities to create own trading strategies, test them in the demo market and apply it in the real market.

\section{Conclusions}

Global finance markets with real time technologies change the traditional perception of time. Trading becomes independent from market working time. The choosing of opening and closing time of finance market is not important in forecasting of exchange rates values.

We investigated new method of forecasting based on London and New York maximal values, which gives additional information for speculators in trading decision making. Developing the innovative predicting tools of exchange markets must be based on data dependent from time zones. So, different time zones can be successfully used in forecasting.

The obtained results show that evaluation of forecasts in different time zones reveals a possible trend in the exchange market and enriches the choice of profitable real-time trading strategies.

\section{References}

Baker, S. D.; Hollifield, B.; Osambela, E. 2016. Disagreement, speculation, and aggregate investment, Journal of Financial Economics 119(1): 210-225. http://dx.doi.org/10.1016/j.jfineco.2015.08.014

Bańbura, M.; Giannone, D.; Lenza, M. 2015. Conditional forecasts and scenario analysis with vector autoregressions for large cross-sections, International Journal of Forecasting 31(3): 739-756. http://dx.doi.org/10.1016/j.ijforecast.2014.08.013

Cetina, K. K. 2005. How are global markets global? The architecture of a flow world. Karin Knorr Cetina/Alex Preda, 38-61.

Cetina, K. K. 2015. What is a financial market? Global markets as media-institutional forms, in P. Aspers, N. Dodd (Eds.). Re-imagining economic sociology. Oxford Scholarship Online, 103-124.

Dacorogna, M. M.; Müller, U. A.; Jost, C.; Pictet, O. V.; Ward, J. R. 1995. Heterogeneous real-time trading strategies in the foreign exchange market, The European Journal of Finance 1(4): 383-403. http://dx.doi.org/10.1080/13518479500000026

Deng, S.; Yoshiyama, K.; Mitsubuchi, T.; Sakurai, A. 2015. Hybrid method of multiple kernel learning and genetic algorithm for forecasting short-term foreign exchange rates, Computational Economics 45(1): 49-89.
Evans, C.; Pappas, K.; Xhafa, F. 2013. Utilizing artificial neural networks and genetic algorithms to build an algo-trading model for intra-day foreign exchange speculation, Mathematical and Computer Modelling 58(5): 1249-1266. http://dx.doi.org/10.1016/j.mcm.2013.02.002

Fan, S.; Hyndman, R. J. 2012. Short-term load forecasting based on a semi-parametric additive model, Power Systems, IEEE Transactions 27(1): 134-141. http://dx.doi.org/10.1109/TPWRS.2011.2162082

Forex market hours. 2006 [online], [cited 10 February 2016]. Available from Internet: http://www.forexmarkethours.com

Fridson, M. S. 2012. The clash of the cultures: investment vs. speculation (a review), Book Reviews 7(1): $1-1$.

Greene, D.; Mierzwa, D.; Abukhater, A.; Sievert, M. 2013. Trade financial corporation. Online trading system having real-time account opening. U.S. Patent $8,538,857$.

Hochreiter, S.; Schmidhuber, J. 1997. Long short-term memory, Neural Computation 9(8): 1735-1780. http://dx.doi.org/10.1162/neco.1997.9.8.1735

Hull, J. C. 2008. Options, futures and other derivatives. 7th ed. London: Pearson Educational Ltd.

Ince, O. 2014. Forecasting exchange rates out-of-sample with panel methods and real-time data, Journal of International Money and Finance 43: 1-18. http://dx.doi.org/10.1016/j.jimonfin.2013.12.004

Joao, R. S.; Guidoni, T. F.; Bertini, J. R.; Nicoletti, M. D. C.; Artero, A. O. 2014. Stock closing price forecasting using ensembles of constructive neural networks, in Intelligent Systems (BRACIS), 2014 Brazilian Conference, 18-23 October 2014, São Carlos, Brasil, 109-114.

Kong, X. T.; Fang, J.; Luo, H.; Huang, G. Q. 2015. Cloud-enabled real-time platform for adaptive planning and control in auction logistics center, Computers \& Industrial Engineering 84: 79-90.

Kvietkauskiene, A. 2014. Real time investments with adequate portfolio theory, Entrepreneurial Business and Economics Review 2(4): 85.

Lall, R. 2015. Timing as a source of regulatory influence: A technical elite network analysis of global finance, Regulation \& Governance 9(2): 125-143. http://dx.doi.org/10.1111/rego.12050

Maknickas, A.; Maknickienè, N. 2012. Influence of data orthogonality: on the accuracy and stability of financial market predictions, in $5^{\text {th }}$ International Joint Conference of Computational Intelligence, 5-7 October 2012, Spain, Barcelona, 616-619.

Maknickas, A.; Maknickienè, N. 2015. Investment support system using the EVOLINO recurrent neural network ensemble, in $7^{\text {th }}$ International Joint Conference of Computational Intelligence, 12-14 November 2015, Lisbon, Portugal, 138-145.

Maknickienè, N. 2014. Selection of orthogonal investment portfolio using Evolino RNN trading model, 
Procedia-Social and Behavioral Sciences 110: 1158-1165.

http://dx.doi.org/10.1016/j.sbspro.2013.12.962

Maknickienė, N.; Maknickas, A. A. 2013. Investigation of prediction capabilities using RNN ensembles, in $5^{\text {th }}$ International Joint Conference of Computational Intelligence, 20-22 September 2013, Vilamoura, Portugal, 391-395.

Masteika, S.; Driaunys, K.; Rutkauskas, A. V. 2013. Historical data formation for back test and technical analysis in North American futures market, Transformations in Business \& Economics 12(1A): 473-488.

Melvin, M.; Prins, J.; Shand, D. 2013. Forecasting exchange rates: an investor perspective, Handbook of Economic Forecasting 2: 721.

Pandey, A. S. 2015. Basic forecasting techniques for currency volatility in changing economic environment, in A. Bansal, Y. Phatak, R. K. Sharma (Eds.). Quality management practices for global excellence. Allied Publishers Pvt. Ltd.

Pulido, M.; Castillo, O.; Melin, P. 2013. Genetic optimization of ensemble neural networks for complex time series prediction of the Mexican exchange, International Journal of Innovative Computing, Information and Control (IJICIC) 9: 4151-4166.

Pulido, M.; Melin, P. 2015. Ensemble neural network optimization using the particle swarm algorithm with type-1 and type-2 fuzzy integration for time series prediction, Fuzzy Logic Augmentation of Nature-Inspired Optimization Metaheuristics 574: 139-149. http://dx.doi.org/10.1007/978-3-319-10960-2_9

Pulido, M.; Melin, P.; Castillo, O. 2014. Particle swarm optimization of ensemble neural networks with fuzzy aggregation for time series prediction of the Mexican Stock Exchange, Information Sciences 280: 188-204.

http://dx.doi.org/10.1016/j.ins.2014.05.006

Radu, S. 2013. Investment versus speculation on stock exchange, Calitatea 14(2): 229.

Rout, M.; Majhi, B.; Majhi, R.; Panda, G. 2014. Forecasting of currency exchange rates using an adaptive ARMA model with differential evolution based training, Journal of King Saud UniversityComputer and Information Sciences 26(1): 7-18. http://dx.doi.org/10.1016/j.jksuci.2013.01.002

Roy, S. S.; Mittal, D.; Basu, A.; Abraham, A. 2015. Stock market forecasting using LASSO linear regression model, Advances in Intelligent Systems and Computing 334: 371-381.

http://dx.doi.org/10.1007/978-3-319-13572-4_31
Rutkauskas, A. V.; Kvietkauskienè, A. 2013. Investment decisions in global financial markets: the experience of Lithuania, Entrepreneurial Business and Economics Review 1(4): 21-35.

Schmidhuber, J.; Gagliolo, M.; Wierstra, D.; Gomez, F. 2006. Evolino for recurrent support vector machines, in European Symposium on Artificial Neural Networks, April 26-28 2006, Bruges, Belgium, 593-598.

Schmidhuber, J.; Wierstra, D.; Gomez, F. 2005. Evolino: Hybrid neuroevolution: optimal linear search for sequence learning, in Proceedings of the $19^{\text {th }}$ International Joint Conference on Artificial Intelligence, 30 August - 5 June 2005, Edinburgh, Scotland, 853-858.

Schmitt, N.; Westerhoff, F. 2014. Speculative behaviour and the dynamics of interacting stock markets, Journal of Economic Dynamics and Control 45: 262-288.

http://dx.doi.org/10.1016/j.jedc.2014.05.009

Sermpinis, G.; Theofilatos, K.; Karathanasopoulos, A.; Georgopoulos, E. F.; Dunis, C. 2013. Forecasting foreign exchange rates with adaptive neural networks using radial-basis functions and particle swarm optimization, European Journal of Operational Research 225(3): 528-540. http://dx.doi.org/10.1016/j.ejor.2012.10.020

Stasytytè, V.; Martinkutè-Kaulienè, R. 2014. Trading futures contracts in global markets, in The $8^{\text {th }}$ International Scientific Conference "Business and Management 2014”, 12-13 May 2014, Vilnius, Lithuania. Vilnius: Technika, 328-335.

Stein, E.; Daude, C. 2007. Longitude matters: Time zones and the location of foreign direct investment, Journal of International Economics 71(1): 96-112. http://dx.doi.org/10.1016/j.jinteco.2006.01.003

Ter Ellen, S.; Verschoor, W. F.; Zwinkels, R. C. 2013. Dynamic expectation formation in the foreign exchange market, Journal of International Money and Finance 37(October): 75-97. http://dx.doi.org/10.1016/j.jimonfin.2013.06.001

Wiener, N. 1923. Differential space, Journal of Mathematical Physics 2(1-4): 131-174. http://dx.doi.org/10.1002/sapm192321131

Wierstra, D.; Gomez, F. J.; Schmidhuber, J. 2005. Modeling systems with internal state using evolino, in Proceedings of the $7^{\text {th }}$ Annual Conference on Genetic and Evolutionary Computation, 25-29 June 2005, Washington, USA, 1795-1802. http://dx.doi.org/10.1145/1068009.1068315 